\title{
Design and Development of Seed Cotton Pre-Cleaner Machinery
}

\author{
Abdurasul Pirnazarov \\ Namangan Institute of Engineering and Technology, Namangan, Uzbekistan \\ Email: abdurasul1981@gmail.com
}

How to cite this paper: Pirnazarov, A. (2021) Design and Development of Seed Cotton PreCleaner Machinery. Engineering, 13, 656-666. https://doi.org/10.4236/eng.2021.1312047

Received: November 2, 2021

Accepted: December 17, 2021

Published: December 20, 2021

Copyright (c) 2021 by author(s) and Scientific Research Publishing Inc. This work is licensed under the Creative Commons Attribution International License (CC BY 4.0).

http://creativecommons.org/licenses/by/4.0/

\begin{abstract}
The process of transporting and cleaning seed cotton is carried out by passing raw materials through many machines. The efficiency of a cleaner machine depends on many factors and mainly machine design. The cleaner machines clean the seed cotton using mechanical forces, and these forces have a negative effect on the quality of the fiber and seeds. This paper provides results of the experimental research to improve the technology of pre-cleaning seed cotton from foreign matters. The results of research were conducted to reduce the number of machines in the cleaning process and design a new pre-cleaner machine.
\end{abstract}

\section{Keywords}

Seed Cotton, Cleaning, Ginning, Fiber, Pneumatic Conveying

\section{Introduction}

Due to its $17 \%$ - $24 \%$ oil and $40 \%$ - $43 \%$ protein contents, the cotton plant provides the most important raw materials for textile, food and feed industries. Cotton production is considered as an important source of Uzbekistan [1].

The main goal of seed-cotton ginning is to separate the fibers from the seeds through three successive general processing which a seed-cotton cleaning step to remove a maximum of trash, a ginning step for separating fibers from the seeds, and a fiber (or lint) cleaning step to extract the remaining trash before a bale pressing operation to form cotton bales. All these processes affect the quality of the produced fibers in variable manners, intensity and direction (positive or negative) [2] [3].

Seed cotton requires multi-stage cleaning because of high foreign-matter content. The seed cotton is harvested with varying amounts of stems, branches, and 
leaf material. Large pieces of foreign matter interfere with the operation of gin stands and have to be removed from the seed cotton before ginning. Smaller foreign-matter particles do not interfere with ginning, but they do lower the quality of the fiber. Effective cleaning systems must be employed to achieve economical ginning performance and to provide acceptable monetary returns to the producer. A series of experiments were conducted by researchers to determine the amount and arrangement of cleaning machinery required to achieve acceptable ginning performance, maximize producer returns, and insure satisfactory end-use performance of fiber [4] [5].

The seed cotton is processed into four main products, namely, fiber, oil, meal, and lint. Most seed cotton processing operations, such as storage, drying, cleaning, transportation use airflow. Pneumatic conveying system plays an important role in handling and processing of seed cotton cleaning. Cleaning, ginning, delinting require a certain pneumatic handling system for conveying seed cotton.

The term seed cotton cleaning refers to the use of various types of cylinder cleaners designed primarily for removal of dirt and small pieces of leaves, bracts, and other vegetative matter, as well as "extractors" that are used to remove large trash, such as burs and sticks, from the seed cotton. The amount of cleaning and extracting machinery required to satisfactorily clean seed cotton varies with the trash content of the seed cotton, which depends in large measure on the method of harvest [6].

The efficiency of a cleaner or extractor depends on many factors, including machine design; cotton moisture level; processing rate; adjustments, speed, and condition of the machine; the amount and nature of trash in the cotton; distribution of cotton across the machine; and the cotton variety. The total trash removal efficiency of cylinder cleaners is generally low compared to extractors when measured by weight of trash, as the trash particles are small. However, they are usually used in combination with other machines. Cylinder cleaners perform a most useful function in opening the cotton and removing fine trash. Studies using both machine-picked and machine-stripped cottons have shown that the total trash removal efficiency of a six-cylinder inclined cleaner with grid rods generally ranges from $10 \%$ to $40 \%$ as measured by weight. Cylinder cleaners known as "hot air" machines also separate conveying and drying air from the seed cotton and require a vacuum dropper to return the cotton to atmospheric pressure. In this case, air is discharged with the trash.

The cleaning efficiencies of extractors vary widely, depending on the condition of the seed cotton and on machine design variables. For machine-stripped cotton, a modern commercial stick machine can be expected to remove about $65 \%$ of the burs, $50 \%$ of the sticks, and $10 \%$ to $35 \%$ of the fine trash. The total cleaning efficiency for stripped cotton is normally in the $60 \%$ to $65 \%$ range. The total cleaning efficiency can range from about $20 \%$ for cleanly picked seed cotton to as high as $50 \%$ for picked cotton containing significant amounts of burs and sticks [7] [8] [9]. 
Extractor-feeders are efficient cleaners. Seed cotton is usually well dispersed when it enters an extractor-feeder, and the feed rate through this machine is often lower than the feed rate of other seed cotton cleaning machinery. Studies wherein all seed cotton cleaners prior to the extractor-feeder were bypassed have indicated that the extractor-feeder removes $70 \%$ of the hulls, $15 \%$ of the motes, and $40 \%$ of the remaining trash components and has an overall cleaning efficiency of about $40 \%$ for machine-picked cotton. Cleaning efficiencies for sequences of four seed cotton machines consisting of a cylinder cleaner, a stick machine, a second cylinder cleaner, and an extractor-feeder range from $40 \%$ to $80 \%$, depending on the factors previously discussed. The amount of each type of trash in cotton also varies substantially. Hand- or spindle-harvested cotton normally contains less than $10 \%$ foreign material. Each type of seed cotton cleaner is designed to remove different types of trash, and any calculation of machine efficiency is predicated on the type of trash involved [10] [11].

In order to design equipment for pre-cleaning, handling, aeration, storing, and processing of cotton seeds, it is necessary to study the effect of mechanical forces to characteristics of cotton seed. In addition, it is necessary to reduce the external forces acting on the seed cotton from the cleaning devices. Thus, the objective of this work was to design of a new machine for pre-cleaning seed-cotton while pneumatic conveying.

\section{Materials and Method}

The seed cotton cleaning factory uses the pneumatic transportation for conveying seed cotton. Pneumatic conveying system is very simple, comfortable and more adapted [12].

The pneumatic conveying system includes following devices: tube 1, stone detector 2, separator 3, ventilator 4, cyclone 5 and unloading tray 6 (Figure 1).

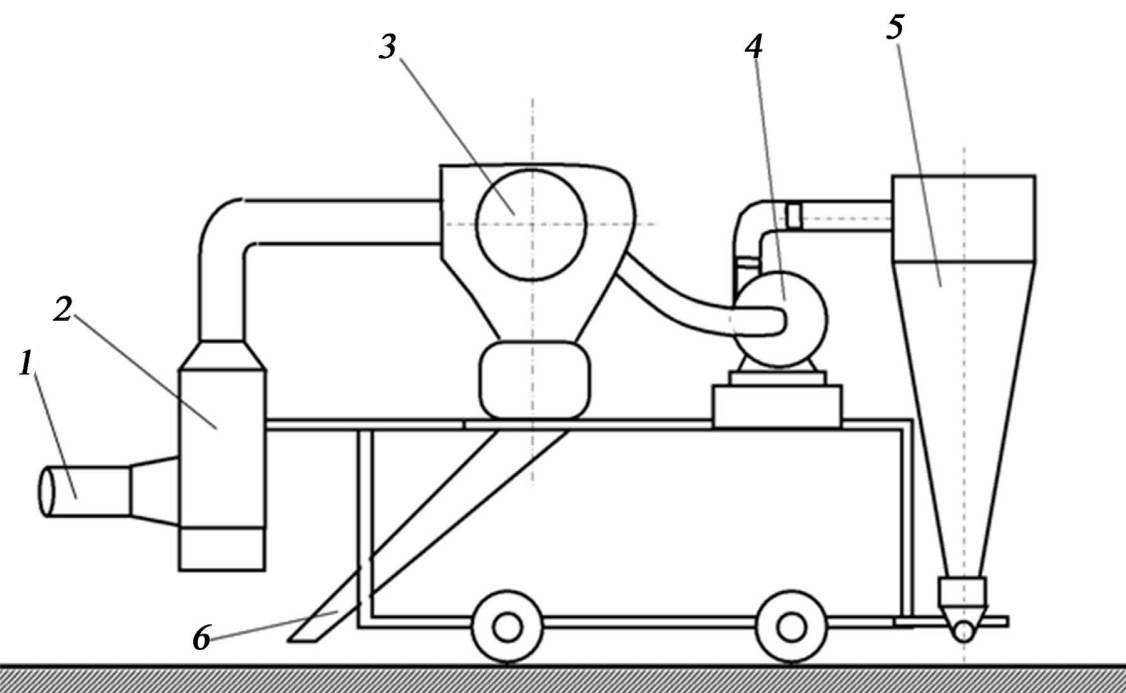

Conduit 1, stone detector 2, separator 3, ventilator 4, cyclone 5 and unloading tray 6.

Figure 1. Layout of pneumatic transport for seed cotton. 
The pneumatic conveying system works as fellows: seed cotton comes from the pile of cotton by tube 1 with air and they inter to stone detector 2 . The seed cotton cleaned from heavy dirty elements in worker chamber of stone detector 2 . Then seed cotton goes to separator 2 by tube 1 . Seed cotton is separated from air there and goes to next machinery by unloading tray 6 . A dusty air goes to cyclone 5 and it is cleaned form dusty there.

\subsection{Theoretical Research}

Figure 2 shows the seed cotton motion on the slope screens in cleaning process. These screens materials, conditions and geometrical parameters have an influence seed cotton quality [13] [14]. Thus, theoretical research done to study a seed cotton motion on the slope shaker screen.

According to Lagrange's principle, we'll be composed differential equation of seed cotton bale steady movements on the screen:

$$
\begin{gathered}
m \ddot{x}_{c}=\sum X=G_{x}+F_{F}+P \\
m \ddot{y}_{c}=\sum Y=N-G_{y} \\
I \ddot{\phi}_{c}=\sum M=-F_{F} R
\end{gathered}
$$

Supplement connection equations:

$$
\begin{aligned}
& Y_{c}=R=\text { const } \\
& \omega=\dot{\phi}=\frac{V_{c}}{R}=\frac{\dot{x}_{c}}{R}
\end{aligned}
$$

It will be differentiated Equation (5) one time:

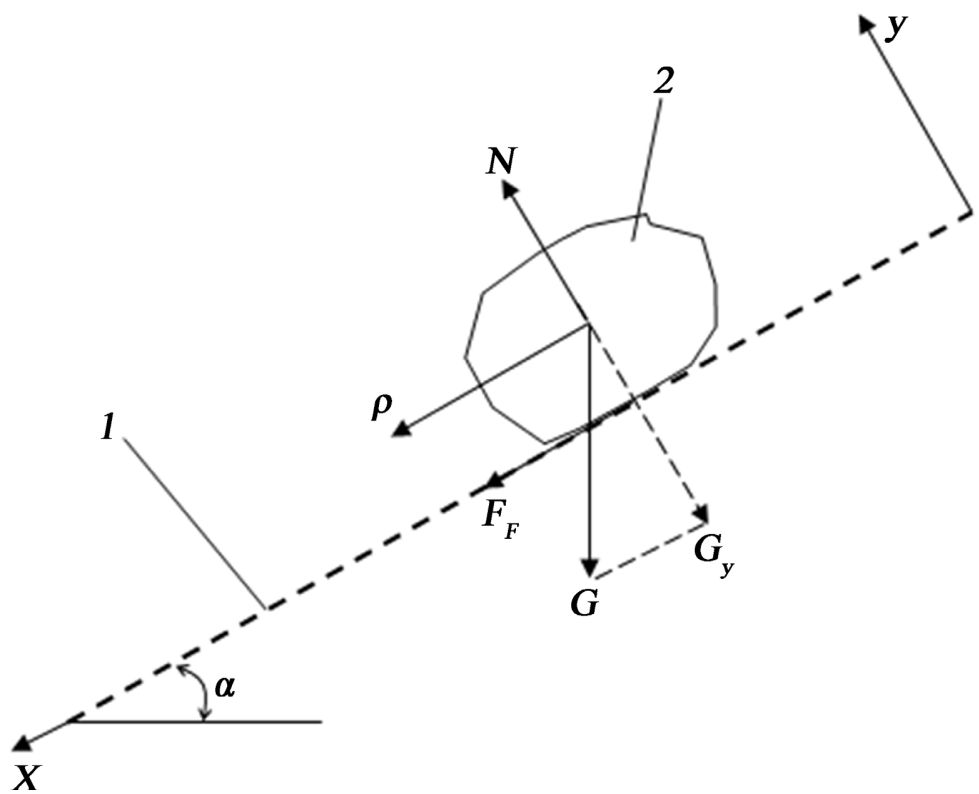

1-shaker screen; 2 -seed cotton boll; $\alpha$-slope angle; $G$ - the force of gravity; $P$-the force of gravity along the screen; $G_{y}-$ the force of gravity perpendicular to the screen; $N$-the normal reaction force.

Figure 2. The seed cotton's boll motion on the slope screen. 


$$
\ddot{\phi}_{c}=\frac{\ddot{x}_{c}}{R}
$$

It will be differentiated Equation (4) two times:

$$
\ddot{y}_{c}=0
$$

We'll put Equation (6) into (3):

$$
I_{c} \frac{\ddot{x}_{c}}{R}=-F_{F} \cdot R \Rightarrow m i_{c}^{2} \frac{\ddot{x}_{c}}{R}=-F_{F} \cdot R \Rightarrow m \ddot{x}_{c}=\frac{-F_{F} \cdot R^{2}}{i_{c}^{2}}
$$

We'll put Equation (1) into (8):

$$
\begin{gathered}
\frac{-F_{F} \cdot R^{2}}{i_{c}^{2}}=m g \sin \alpha+F_{F}+P \Rightarrow-\left(R^{2} F_{F}+i_{c}^{2} F_{F}\right)=m g i_{c}^{2} \sin \alpha+P i_{c}^{2} \\
F_{F}=\frac{i_{c}^{2} m g \sin \alpha+P i_{c}^{2}}{R^{2}+i_{c}^{2}}
\end{gathered}
$$

We'll put Equation (7) into (2):

$$
N-G_{y}=0 \rightarrow N=G_{y}=m g \cos \alpha
$$

From Equation (10):

$$
F_{F}=-\frac{i_{c}^{2} m g \sin \alpha}{R^{2}+i_{c}^{2}}-\frac{i_{c}^{2}}{R^{2}+i_{c}^{2}} \cdot P
$$

This equation shall be given frictional force of seed cotton bale movement on the screen with $\mathrm{P}$ force which affect to it.

\subsection{Design}

The thread is smooth and stronger when cotton fibers have a high quality. In the cotton fabric of while cleaning and ginning used from saw dram, stick dram, wire mesh screen. They mechanical and dynamical affect to cotton fiber and damage it. For that reason, we have invented a new pre-cleaner for seed cotton machinery that cleaning seed cotton by ellipse drum and shaker screens.

The lab stand of the shaker pre-cleaner for seed cotton has been developed by the department "technological machines and equipment" of Namangan Institute of Engineering and Technology.

The pre-cleaner stand for testing is built with different numbers of mechanisms those are shaker bar screen 1, ellipse drum 2, horizontal shaker screen 3 (Figure 3, Figure 4).

It can be applied in several different arrangements and their use allows the seed cotton slipping to decrease as it is being mechanically cleaned and conveyed.

Seed cotton samples were collected before and after cleaning. The foreign matter content of the seed cotton samples was determined using the fractionation method, and the moisture content of the seed cotton was determined using the oven drying method.

The stand works as follows: when seed cotton comes into this machine, it is cleaned from heavy dirty on the shaker bar screen 1 . Then seed cotton drop on 


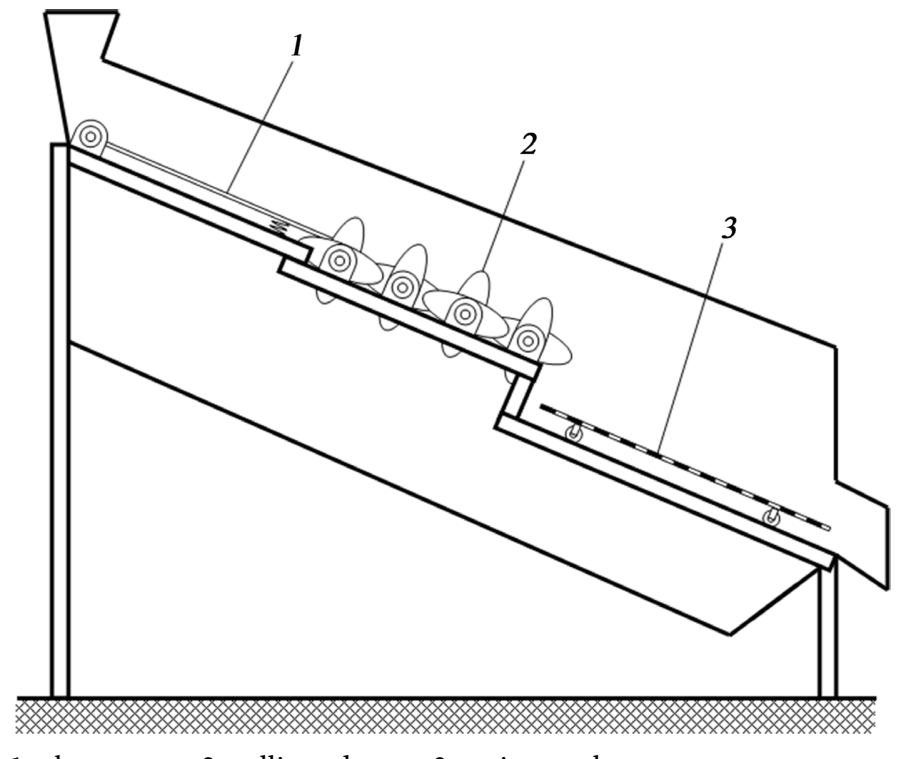

1-bar screen, 2-ellipse drums, 3-wire mesh screen.

Figure 3. A drawing of a new pre-cleaner machinery for seed cotton.

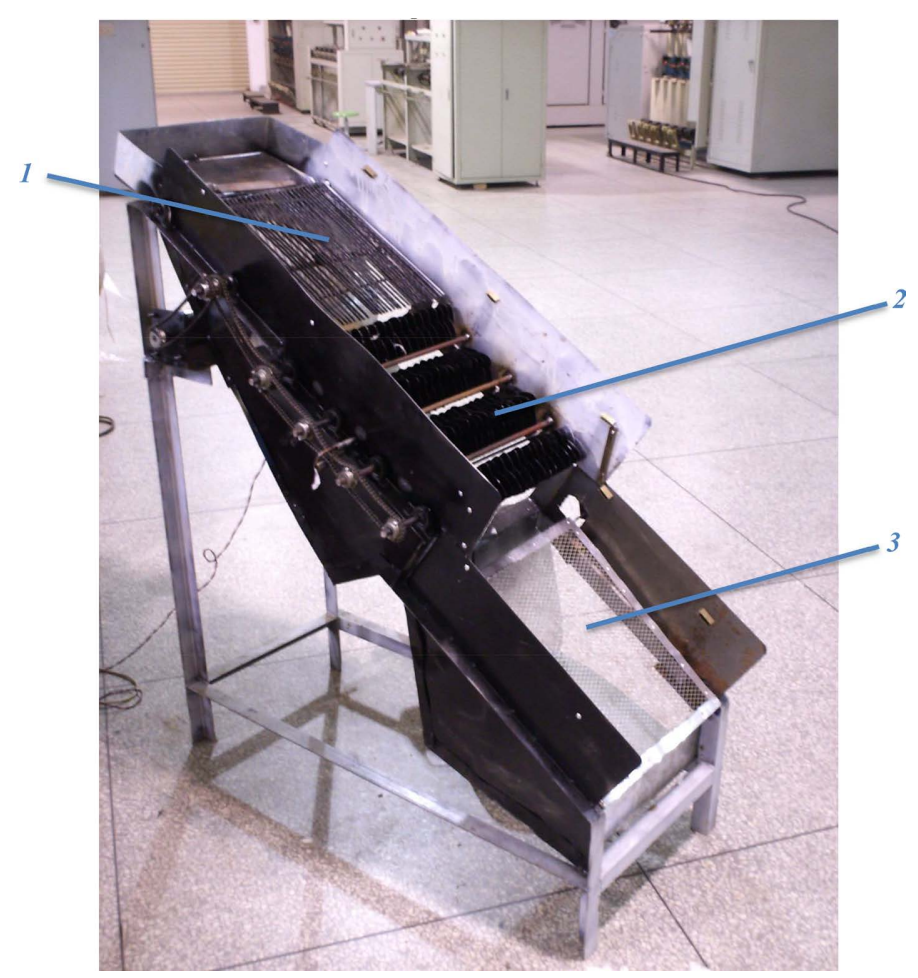

1-bar screen, 2-ellipse drums, 3-wire mesh screen.

Figure 4. A new machinery of pre-cleaning.

the ellipse dram 2 to more cleaned of cotton. The horizontal shaker screens 3 cleans seed cotton more. Separated foreign-matter gets out by seed cotton output tray.

\section{Results and Discussion}

The lab experiments on the shaker pre-cleaner have been done to study the in- 
fluence of the shaker screens design and incline angle to the cleaning efficiency. To assess the effectiveness of the different shaker screen and ellipse drums regimes used, seed-cotton and lint samples were collected during the 2020-2021 ginning season for foreign matter and fiber quality analyses. While cleaning, each cleaner section (mechanism) separated trash and a quality analyses sample of seed cotton were taken at the various frequency and amplitude of shaker screen.

Because there was no significant interaction between frequency and inclination angle of the shaker screen, the data was analyzed by amplitude and inclination angle of the shaker screens separately.

Table 1 shows the influence of inclination angle on effectiveness of cleaning seed cotton during the experiment. The inclination angle changing was significantly different among the seed cotton cleaning treatments. Seed cotton foreign

Table 1. The influence of inclination angle on effectiveness of cleaning.

Frequency of shaker screen 1: $\omega=4 \mathrm{~Hz}$

Amplitude of shaker screen 2: $A=3 \mathrm{~mm}$

\begin{tabular}{|c|c|c|c|c|c|}
\hline \multirow{2}{*}{ № } & \multirow{2}{*}{$\begin{array}{c}\text { Moisture of } \\
\text { seed cotton, \% }\end{array}$} & \multicolumn{4}{|c|}{ The separated trash, gram } \\
\hline & & Shaker screen 1 & Ellipse drum & Shaker screen 2 & Amount \\
\hline & $\alpha=20^{\circ}$ & & & & \\
\hline 1. & & 39.7 & 42.4 & 16.1 & 98.2 \\
\hline 2. & & 38.8 & 41.3 & 15.9 & 96.0 \\
\hline 3. & $W_{c}=8 \%$ & 38.5 & 41.6 & 15.6 & 95.7 \\
\hline 4. & & 38.3 & 42.2 & 15.7 & 96.2 \\
\hline 5. & & 39.4 & 41.8 & 15.8 & 97.0 \\
\hline & Total & 38.9 & 41.9 & 15.8 & 96.6 \\
\hline & $\alpha=30^{\circ}$ & & & & \\
\hline 1. & & 38.9 & 41.3 & 14.9 & 95.1 \\
\hline 2. & & 38.4 & 41.4 & 15.4 & 95.2 \\
\hline 3. & $W_{c}=8 \%$ & 38.7 & 41.2 & 15.2 & 95.1 \\
\hline 4. & & 38.5 & 40.9 & 15.1 & 94.5 \\
\hline 5. & & 39.1 & 41.6 & 15.3 & 96.0 \\
\hline & Total & 38.7 & 41.2 & 15.1 & 95.1 \\
\hline & $\alpha=40^{\circ}$ & & & & \\
\hline 1. & & 37.6 & 38.4 & 12.7 & 88.7 \\
\hline 2. & & 37.1 & 38.8 & 11.8 & 87.7 \\
\hline 3. & $W_{c}=8 \%$ & 37.4 & 39.2 & 12.3 & 88.9 \\
\hline 4. & & 36.8 & 39.3 & 12.1 & 88.2 \\
\hline 5. & & 37.3 & 38.7 & 11.7 & 87.7 \\
\hline & Total & 37.2 & 38.9 & 12.1 & 88.2 \\
\hline
\end{tabular}


matter content at the inclination angle was $\alpha=20^{\circ}$ among cleaning treatments having the highest separated trash content at $96.6 \%$.

There were differences in seed cotton foreign matter content after various frequency of shaker screen of seed cotton cleaning treatments (Table 2). Trash content at the higher frequency among the shaker screens was highest under ellipse drums that contained averaged 42.3 grams.

Table 3 shows the influence of amplitude of shaker screen 2 on effectiveness of cleaning. Total foreign matter content of the seed cotton was different amplitudes. The cleaning treatment with the $A=2 \mathrm{~mm}$ screen shaking fast had the highest amount of foreign matter $(5.1 \%)$ in the seed cotton; this is reasonable because the 3-sm screen shaking fast had the highest trash content under both the screens, and some of the trash goes with the seed cotton. The seed cotton

Table 2. The influence of frequency of shaker screen 1 on effectiveness of cleaning.

Inclination angle Frequency of shaker screen 1: $\alpha=30^{\circ}$ Amplitude of shaker screen 2: $A=3 \mathrm{~mm}$

\begin{tabular}{|c|c|c|c|c|c|}
\hline \multirow{2}{*}{ № } & \multirow{2}{*}{$\begin{array}{c}\text { Moisture of } \\
\text { seed cotton, \% }\end{array}$} & \multicolumn{4}{|c|}{ The separated trash, gram } \\
\hline & & Shaker screen 1 & Ellipse drum & Shaker screen 2 & Amount \\
\hline & $\omega=2 \mathrm{~Hz}$ & & & & \\
\hline 1. & & 36.4 & 41.6 & 15.6 & 93.6 \\
\hline 2. & & 36.7 & 42.3 & 15.7 & 94.7 \\
\hline 3. & $W_{c}=8 \%$ & 37.0 & 42.4 & 15.3 & 94.7 \\
\hline 4. & & 36.5 & 42.2 & 15.4 & 94.1 \\
\hline 5. & & 36.6 & 41.7 & 15.8 & 94.1 \\
\hline & Total & 36.6 & 42.0 & 15.5 & 94.2 \\
\hline & $\omega=4 \mathrm{~Hz}$ & & & & \\
\hline 1. & & 38.2 & 42.5 & 15.7 & 96.4 \\
\hline 2. & & 38.7 & 42.0 & 15.4 & 96.1 \\
\hline 3. & $W_{c}=8 \%$ & 38.5 & 41.9 & 15.6 & 96.0 \\
\hline 4. & & 38.9 & 42.3 & 15.3 & 96.5 \\
\hline 5. & & 36.6 & 41.8 & 15.8 & 94.2 \\
\hline & Total & 38.2 & 42.1 & 15.6 & 95.8 \\
\hline & $\omega=6 \mathrm{~Hz}$ & & & & \\
\hline 1. & & 38.6 & 42.3 & 15.2 & 96.1 \\
\hline 2. & & 38.3 & 42.6 & 15.3 & 96.2 \\
\hline 3. & $W_{c}=8 \%$ & 38.2 & 42.1 & 15.5 & 95.8 \\
\hline 4. & & 38.4 & 42.4 & 15.3 & 96.1 \\
\hline 5. & & 38.7 & 42.1 & 15.6 & 96.4 \\
\hline & Total & 38.4 & 42.3 & 15.4 & 96.1 \\
\hline
\end{tabular}


Table 3. The influence of amplitude of shaker screen 2 on effectiveness of cleaning.

Inclination angle Frequency of shaker screen 1: $\alpha=30^{\circ}$

Frequency of shaker screen 1: $\omega=4 \mathrm{~Hz}$

\begin{tabular}{|c|c|c|c|c|c|}
\hline \multirow{2}{*}{ № } & \multirow{2}{*}{$\begin{array}{c}\text { Moisture of } \\
\text { seed cotton, \% }\end{array}$} & \multicolumn{4}{|c|}{ The separated trash, gram } \\
\hline & & Shaker screen 1 & Ellipse drum & Shaker screen 2 & Amount \\
\hline & $A=2 \mathrm{~mm}$ & & & & \\
\hline 1. & & 37.7 & 42.2 & 15.1 & 95.0 \\
\hline 2. & & 38.2 & 41.7 & 15.2 & 95.1 \\
\hline 3. & $W_{c}=8 \%$ & 37.7 & 41.9 & 14.9 & 94.5 \\
\hline 4. & & 37.9 & 42.1 & 15.0 & 95.0 \\
\hline 5. & & 37.6 & 42.3 & 15.3 & 95.2 \\
\hline & Total & 37.8 & 42.04 & 15.1 & 94.9 \\
\hline & $A=3 \mathrm{~mm}$ & & & & \\
\hline 1. & & 36.8 & 42.4 & 15.8 & 95.0 \\
\hline 2. & & 37.5 & 42.2 & 15.4 & 95.1 \\
\hline 3. & $W_{c}=8 \%$ & 37.1 & 42.3 & 15.7 & 95.1 \\
\hline 4. & & 37.9 & 42.1 & 15.3 & 95.3 \\
\hline 5. & & 37.2 & 42.3 & 15.5 & 95.0 \\
\hline & Total & 37.3 & 42.3 & 15.5 & 95.1 \\
\hline & $A=4 \mathrm{~mm}$ & & & & \\
\hline 1. & & 37.7 & 42.3 & 15.4 & 95.4 \\
\hline 2. & & 37.9 & 41.9 & 15.5 & 95.3 \\
\hline 3. & $W_{c}=8 \%$ & 37.5 & 42.2 & 15.6 & 95.3 \\
\hline 4. & & 37.8 & 41.8 & 15.7 & 95.3 \\
\hline 5. & & 37.6 & 42.0 & 15.5 & 95.1 \\
\hline & Total & 37.7 & 42.0 & 15.6 & 95.3 \\
\hline
\end{tabular}

cleaning treatment with $A=4 \mathrm{~mm}$ screen shaking had the lowest amount of foreign matter in the seed cotton (4.7\%), and as increasing amplitude of shaker screens, foreign matter content decreased.

\section{Conclusions}

The seed cotton cleaning industry has rapidly changed for five decades and the number of cleaners has fallen by nearly $50 \%$. There were very few similarities in machinery set-up for seed-cotton cleaning. Most cleaning treatments use stick or cylinder cleaners and an air-type cleaner for seed cotton cleaning. The trend in seed cotton cleaning today seems to be toward aggressive seed-cotton cleaning and gentle cleaning to limit fiber damage. 
Seed cotton property measurements were taken before and after cleaning showed that, in general, pre-cleaning machinery reduced foreign matter content in seed cotton and fiber. Also, cleaning machines tended to reduce fiber length and increase neps.

Seed cotton trash content at the bar screen, ellipse drums and wire mesh screen were different among cleaning treatment with the 2 -sm amplitude having more trash than the 4-mm spindle. This is consistent with the theory that higher amplitude has more trajectory and does not compress the seed cotton boll as much due to a longer way. Inclination angle was shown to have a huge impact on seed-cotton cleaning, increasing the inclination angle reduces cleaning efficiency.

Ellipse drums had a significant impact on cleaning efficiency. The number of ellipse drum and total number of ellipse that the fiber encountered during seed cotton cleaning were significantly separated into boll and tufts. It affects the seed cotton cleaning efficiency proportional.

In summary, there were important and significant differences between screens and ellipse drums made for the pre-cleaner stand. These differences are related to processing efficiency in both the cleaning process as well as the ginning process for higher quality fibers. Further testing needs to be done to determine what full scale design parameters contribute to the significantly different cleaning and conveying process performance.

\section{Acknowledgements}

I would like to thank my supervisor professor Rustam Muradov for his valuable advice for the improvement of this article.

\section{Conflicts of Interest}

The author declares no conflicts of interest regarding the publication of this paper.

\section{References}

[1] Usmonov, X.S., Abbozov I.Z. and Sirojjidinov, F.N. (2019) Analysis of Factors Influencing on Increasing the Efficiency of Cotton Cleaning. Textile Journal of Uzbekistan, 5, Article No. 1.

[2] Jurayeva, G., Muradov, R. and Abduvohidov, M. (2021) Research of the Issue of Lightening the Construction of the Gin Saw Cylinder. Engineering, 13, 224-235. https://doi.org/10.4236/eng.2021.134017

[3] Rustam, M., Abdusamat, K. and Botir, M. (2014) Theoretical and Experimental Studies of the Effect of Inclined Scraper on Removal of Raw Cotton from Mesh Surface. World Journal of Mechanics, 4, 371-377. https://doi.org/10.4236/wjm.2014.412036

[4] Patil, P.G., Anap, G.R. and Arude, V.G. (2006) Design and Development of Cylinder Type Cotton Pre-Cleaner. International Journal of Agriculture Mechanization in Asia, Africa and Latin America, 37, 46-51.

[5] Armijo, C.B., Baker, K.D., Hughs, S.E., Barnes, E. and Gillum, M.N. (2009) Harvesting and Seed Cotton Cleaning of a Cotton Cultivar with a Fragile Seed Coat. The Jour- 
nal of Cotton Science, 13, 158-165.

[6] Rajapova, N., Tursunov, I., Mardonov, B. and Sarimsakov, O. (2020) The Study of the Movement of the Aero Mixture through the Pipeline during Pneumatic Transportation. Journal of Advanced Research in Dynamical and Control Systems, 12, 1287-1297. https://doi.org/10.5373/JARDCS/V12SP4/20201605

[7] Whitelock, D.P., Armijo, C.B., Gamble, G.R. and Hughs, S.E. (2007) Survey of SeedCotton and Lint Cleaning Equipment in U.S. Roller Gins. The Journal of Cotton Science, 11, 128-140.

[8] Hughs, S.E. and Armijo, C.B. (2015) Impact of Gin Saw-Tooth Design on Fiber and Textile Processing Quality. The Journal of Cotton Science, 19, 27-32.

[9] Armijo, C.B., Whitelock, D.P., Funk, P.A. and Martin, V.B. (2019) How Current Cotton Ginning Practices Affect Fiber Length Uniformity Index. The Journal of Cotton Science, 23, 66-77.

[10] Obidov, A., Sultonov, M., Muhksinov, I. and Abdullaev, S. (2018) The Theoretical Studies of the Cultivation of Three Cotton Seeds along the Plain. Engineering, 10, 514-520. https://doi.org/10.4236/eng.2018.108037

[11] Whitelock, D.P., Armijo, C.B., Boykin, J.C., Buser, M.D., Holt, G.A., Barnes, E.M., Valco, T.D., Findley, D.S. and Watson M.D. (2011) Beltwide Cotton Quality before and after Lint Cleaning. Journal of Cotton Science, 15, 282-291.

[12] Vandergriff, A.L. (1997) Ginning Cotton: An Entrepreneur's Story. Texas Tech University Press, Illustrated, 293.

[13] Obidov, A., Mamatqulov, O. and Sultonov, M. (2018) Theoretical Analysis of the Movement of Cotton Piece on the Slope Surface. International Conference of Science and Practice: A New Level of Integration in the Modern World, Berlin, 2018, 151-156.

[14] Obidov, A. and Sultonov, M. (2021) Theoretical Study of Seed Movement in Cotton Seeds Selection Device. Engineering, 13, 544-553.

https://doi.org/10.4236/eng.2021.1310039 